COMENTARIOS SOBRE EL LIBRO: EL MUEBLE DE MADERA DOMINICANO, DE LA AUTORÍA DE ANGÉLICA MARÍA RODRÍGUEZ BENCOSME

\title{
Luis Toirac
}

Angélica Rodríguez nació en Santo Domingo. Es egresada de la carrera de Diseño Arquitectónico de la Universidad Iberoamericana (UNIBE). Además realizó un postgrado en la Universidad Politécnica de Cataluña (UPC), España, poseedora de un título peculiar: Habitar la casa: Una aproximación interdisciplinaria al conocimiento del espacio doméstico, cuyo nombre abre campo a la imaginación. Posee una maestría en Diseño Industrial con especialidad en Mobiliario, por la Universidad de Nebrija, España. Posee además una maestría en educación superior por el Instituto Tecnológico de Monterrey, empujada por su interés en desarrollar su carrera como profesora de Educación Superior, oficio que a todas luces, la llena de satisfacción. En la actualidad es profesora de varias asignaturas relacionadas con el área de diseño, mobiliario y presupuesto, tanto en INTEC, como en UNIBE e INFOTEP. Su práctica docente ha sido reseñada ampliamente en la prensa local, a través de los periódicos Hoy, Diario Libre y Listín Diario entre otros, así como en medios internacionales, destacándose la Agencia de Noticias para la Divulgación de la Ciencia y Tecnología (DiCYT) y la revista La Casa.

Desde inicios de 2010 es autora de una columna en el periódico Hoy denominada: "Pregúntale a la interiorista". En esta columna 
establece un diálogo permanente con lectores y profesionales, describiendo y analizando de forma concurrente temas relacionados con el mundo del diseño en general, y sobre el mobiliario local en particular.

Angélica ha realizado múltiples investigaciones, seminarios, talleres y charlas, relacionadas con el mueble dominicano. Entre estas destacan: Innovation in Product Design: A Case Study on Dominican Furniture (2009) y Green Furniture, Still Green in Dominican Republic (2012). Como podrá apreciarse, la autora es diseñadora, profesora, investigadora, periodista, escritora y -aunque no posee el título de antropóloga o socióloga- es una apasionada de la exploración de las tradiciones productivas dominicanas, así como del contexto en que se desenvuelven en la actualidad las comunidades productivas, empresas y talleres. Sueña con que el país pueda desarrollar sus capacidades para elaborar productos que sean útiles, y a la vez expresen la cultura e identidad de nuestra gente.

Pero todo esto es más o menos conocido por sus relacionados y los centros académicos y culturales entre los que Angélica se desenvuelve. Lo que no mucha gente sabe sobre ella es que también es ebanista, graduada del INFOTEP, donde aprendió los pormenores del oficio, aprovechando al máximo las oportunidades brindadas por maestros y técnicos. En otras palabras, es capaz de construir muebles con sus propias manos, y de concebir sus propios diseños, incorporando criterios estéticos y técnicos tanto en relación al producto, como en términos de los procesos de fabricación, ya sean estos artesanales o industriales. Como resultado de tan inquietante búsqueda, la autora posee un perfil muy particular, que combina sus conocimientos teóricos y prácticos, pudiendo abarcar con su mirada los aspectos técnicos inherentes al diseño, las especificidades productivas, las características físicomecánicas de la madera y otros materiales, así como las condiciones sociales e históricas que inciden en el desarrollo y producción del mueble. 
Al conocimiento adquirido durante todos estos años, se ha sumado una experiencia personal como emprendedora de una pequeña empresa de muebles, que le ha permitido contar con una experiencia visceral que enriquece continuamente su quehacer profesional. Esta experiencia -pienso-, le ha permitido a la autora poder observar con detenimiento las características de la industria del mueble, sus problemáticas y potencialidades desde una perspectiva integradora. Intuyo que este caleidoscopio de imágenes y experiencias es lo que le ha permitido escribir El mueble de madera dominicano: Análisis, referencias y perspectivas publicado por el fondo editorial del INTEC, publicado en abril de 2013.

El libro abarca las distintas esferas relacionadas con el mobiliario local; la fabricación de muebles a través de la cadena de suministro; la disponibilidad de materias primas locales, hasta el servicio postventa, y los requisitos para su comercialización. Sus páginas permiten comprobar que Angélica se ha tomado el tiempo para elaborar un compendio de las instituciones relacionadas con el sector desde sus distintos ámbitos de acción; de índole legal, institucional, comercial, gremial y técnico. Dedica un capítulo específico para describir las instituciones encargadas de formar los ebanistas y diseñadores del país, dada la importancia que reviste para lograr elevar la competitividad en el sector. De igual modo incluye un capítulo para describir las instituciones nacionales e internacionales que han influido en el sector o poseen roles de importancia en la actualidad. En este sentido auguro que servirá de referencia para toda aquella persona que desee conocer e involucrarse con el sector, para registrar una marca o exportar, así como para los investigadores, estudiantes y profesionales vinculados con la industria del mueble.

La autora ofrece una panorámica sobre aspectos tan importantes para la industria como el diseño, pues plantea que este debería estar al centro de una visión estratégica que permita relanzar el sector. Tiene la valentía de expresar los puntos en los que 
considera el país ha quedado desfasado, y de presentar la ruptura que existe entre las tendencias mundiales y la fabricación local. En la página 72 indica que: "La novedad es un recurso accesible y fácil de implementar en el proceso de desarrollo del mueble, que ha sido enormemente subutilizado por la industria local. Y lo que es peor, la cultura empresarial del industrial del mueble constantemente da muestras de su desconfianza en la novedad como recurso". La autora subraya las razones que, a su juicio, provocan esta situación, y relaciona estas ideas con los planteamientos de Cooper (2001), señalando las jerarquías existentes en los niveles de novedad. Añade que quizás el plagio de diseños, tan común en el país, sea la razón por la cual las Mipymes prefieren trabajar aisladas, desconfiando unas de las otras y desconociendo las ventajas de asociarse.

No obstante, destaca que es en las mismas características locales donde subyace la posibilidad de lograr un renacimiento del sector, partiendo de potencialidades hasta ahora dormidas o desconocidas. Una idea relevante que se destaca en el libro, y que debería estar presente en la agenda de las autoridades nacionales, es el hecho de que la especialización productiva de una región, o las aglomeraciones de unidades productivas en un espacio geográfico determinado, deben ser capitalizadas para crear mayor riqueza. Cita ejemplos urbanos como el barrio de Villa Consuelo, reconocido ya como un pequeño distrito maderero. También hay ejemplos en el interior del país, en zonas como Zambrana o el Plan Sierra. En el primer caso la aglomeración es convocada por la cercanía del mercado y, en el segundo, por la cercanía de las materias primas. El potencial generador de empleo es enorme. En la actualidad, a pesar de la crisis evidente del sector, la autora indica que el sector representa el 1\% del PIB y el 10\% del empleo manufacturero, según estudios locales.

Para que se tenga una idea del rezago del sector me permito citar un estudio realizado en el año 1974 por la Fundación Dominicana 
de Desarrollo (FDD), como base para el establecimiento de su Plan de Desarrollo Artesanal (PLANARTE). Ya entonces indicaba que: "La industria artesanal en $\mathrm{RD}$, en la mayoría de los casos, adolece de organización, originalidad, control de calidad, canales de distribución apropiados, y otros aspectos vitales para que se convierta en una actividad de importancia económica y social". Agrega que "esta situación es paradójica si consideramos las diversas materias primas, actualmente en desuso con referencia a su capacidad de rendimiento, así como el potencial humano disponible que se encuentra desempleado y sub-empleado, especialmente en la zona rural". La cita se ajusta perfectamente a la situación actual del país, que en cuatro décadas no ha podido transformarse positivamente.

El libro de Angélica Rodríguez Bencosme nos coloca ante un espejo en el que podemos apreciar estas mismas imágenes, las cuales deberían atormentar nuestras madrugadas, pues denotan nuestra incapacidad de ponernos de acuerdo en estrategias que promuevan el verdadero desarrollo de la industria local.

En los aspectos relacionados con la comercialización del producto, ofrece una radiografía de la situación nacional, incorporando elementos concatenados, y ofreciendo estadísticas de importación y exportación para presentar al lector una visión global. Presenta además los acuerdos comerciales existentes, las normas y reglamentos necesarios para satisfacer los distintos mercados, con los factores que inciden en el precio y las estratégicas de promoción más utilizadas en el país.

Este tipo de libro ha sido de escasa presencia en el escenario nacional. Podría decirse que la producción nacional no tiene quien le escriba; al menos hasta ahora. Una búsqueda en las principales bibliotecas del país o en internet, permitirá comprobar que la bibliografía existente es limitada y en gran medida se ha generado a partir de financiamientos y donaciones de organismos internacionales, tales como el PNUD, la UE, BID, USAID, entre otros. 
Estos [esfuerzos] se traducen en forma de estudios e informes, pero no así en libros que puedan servir para explicar lo que ha sucedido en términos de la promoción de la industria local y, en especial, de la industria del mueble. Más aún, en manuales técnicos y de fabricación, que atiendan a las especificidades locales. No obstante, una visita a la página www.muebledominicano.com, nos permite vislumbrar una ventana para el cambio, pues subterráneamente pareciera estar gestándose una dinámica distinta, fresca, con visos transformadores.

La industria del mueble posee una amplia presencia en la dinámica nacional, pues en cada barrio, en cada pueblo, existen talleres y empresas que continúan fabricando a pesar de la avalancha de productos importados. En este sentido, la autora también expone las causas que explican el hecho de que los dominicanos no hayan descartado del todo los muebles de madera sólida, dada las características de la vida cotidiana y del clima de la Isla. En la página 98 dice: "El mueble es un objeto con muchas caras y rara vez mudo; refleja las preferencias estéticas y los valores de la sociedad que lo crea." La frase es el preámbulo de una idea central de la obra:

"Por ser el mueble un objeto cultural, nos parece que su producción podría ser un instrumento de inclusión social por diversas razones entrelazadas entre sí:" (debido a que):

- El mueble es parte imprescindible del hogar.

- Fabricar muebles demanda una inversión relativamente baja.

- El mueble no es un producto perecedero.

- La ebanistería es un oficio que puede aprenderse sin necesidad de los agentes de promoción.

- Popularidad de los cursos pertenecientes o afines al sector: tapicería, ebanistería, pintura, cojinería, etc. 
- Producto asequible en términos de que la ideación puede ser llevada a la ejecución con facilidad.

El diseño dominicano, como es de esperar, responde a realidades socioeconómicas y culturales locales. De esta manera, la autora entiende que se constituye en un frente al proceso de homogenización que trae consigo la globalización. Esta realidad, consciente o inconscientemente es la que permite todavía, a pesar de todas las limitaciones, que siga fabricándose en el país. En este orden de ideas, la autora insiste en el hecho de que el diseño es un activo que permite enfrentar a países desarrollados en el contexto del mercado nacional. Esto así porque el mueble transmite una identidad que no es posible copiar fácilmente.

En otras palabras, la creación de un producto responde a la internacionalización de la cultura en forma creativa, expresada materialmente, pues es capaz de transmitir rasgos culturales y especificidades incluso a nivel regional. En este sentido es importante que sean preservados y rescatados los valores culturales que posibiliten conceptualizar estéticamente la obra, pero considerando que la producción sea viable económicamente. Para esto es indispensable que se establezca una retribución adecuada de los diferentes agentes sociales que participan de la producción. Esto deviene en lograr un equilibrio en la transferencia de excedentes desde la esfera productiva a las esferas comerciales y financieras. El reto es entonces lograr capitalizar esta correlación y establecer un proceso de cooperación e innovación permanentes que sean extensible a sectores importantes de la industria. La capacidad de crear nuevos diseños con estas características sería la base para el crecimiento sostenido de la industria, sumado a una mejora sustancial del flujo productivo, la calidad y el servicio de entrega.

De aquí que la autora, en la página 102 destaque lo siguiente: "El mueble, como un objeto que refleja las preferencias estéticas y los valores de la sociedad que lo crea, como parte del folklore 
material de un pueblo, es un producto que podría erigirse como marca país. Abunda: la creatividad es un atributo universal disponible para todos, sin excluir minorías, pero una estrategia sin plan solo es un deseo". La cita no requiere explicación.

La autora plantea una connivencia entre la fabricación artesanal y la fabricación automatizada en función de la determinación de los nichos de mercado adecuados. El diseño desempeña un papel central en la articulación de los procesos de trabajo de las distintas empresas y sectores económicos. Importante es destacar que los bienes de capital desempeñan un rol importante también en este esquema. El crecimiento del sector debe ir de la mano con la articulación entre las empresas de transformación y empresas de fabricación de maquinaria o que brindan servicios técnicos. Es necesario revertir el rezago tecnológico y establecer lazos estrechos entre los productores y los avances en las áreas de diseño y fabricación.

La autora presenta como un error el hecho de que el industrial dominicano concentre sus esfuerzos solo en la reducción de costos para lograr un producto barato, restando importancia al diseño para la creación de valor y por ende, para un incremento en el ratio entre valor de venta y costo. Cita un artículo de Bruce \& Daly donde se ha demostrado que "invertir en diseño incrementa las ventas en más de un 41\% y que en el $90 \%$ de los nuevos diseños son rentables". Me permito ampliar el dato -también en el país- afirmando que, entre 14 empresas estudiadas, quedó demostrado que aquellas que poseían personal dedicado a diseño y/o ingeniería de producto, poseen una productividad alrededor de 2:1 mayor que aquellas que no lo poseen. (Véase, Toirac Troncoso, 2013).

En la obra existe un trasfondo que constituye uno de sus grandes aportes (y que puede apreciarse sobre todo en el último capítulo). La autora ha propuesto que el diseño sea considerado como un eje central en 
el desarrollo de la producción nacional. Ha justificado sus planteamientos a partir de los elementos que su visión le ha permitido formar. Le favorece el hecho de conocer los pormenores del trabajo manual e intelectual. Ambas esferas del conocimiento, que generalmente están disociadas, pueden ser abordadas con éxito por la autora. Queda un amplio campo de acción por definir, dado que es una tarea de la colectividad ligada tanto al diseño como a la fabricación de muebles a todo lo largo de la cadena de suministro. Por eso se pregunta en una de las páginas del libro: “¿podemos los diseñadores convocar a nuestros técnicos y asociarnos para fabricar muebles?" Inmediatamente responde: "la disposición de la gente para cooperar en el logro de un objetivo común es una ventaja competitiva esencial y un recurso para el crecimiento."

Angélica Rodríguez Bencosme nos entrega su experiencia y su visión sobre una industria que merece mejor suerte. Ha plasmado sus ideas sobre lo que ha podido aprender de la industria, pero también con la esperanza de despertar un debate entre los actores y agentes económicos y académicos, para encontrar formas viables de mejorar la productividad, la competitividad y la proyección del sector.

Este libro ofrece una visión de los principales aspectos de la industria en el país. No es un manual pormenorizado, ni un compendio. Un vistazo de la bibliografía utilizada permite apreciar que el trabajo de investigación ha sido amplio y bien documentado. Ojalá que en un futuro cercano otros autores, profesores, investigadores, estudiantes, se animen a escribir sobre estos temas, no solo con relación a la industria del mueble, sino a otras industrias. Rodríguez Bencosme ha abierto una puerta para que podamos vislumbrar aspectos esenciales de nuestra propia industria. 
El lector no se desilusionará ante la realidad que presenta este libro; al contrario se le invita a criticarlo, a desmenuzarlo, a contribuir con sus ideas a mejorar la industria del mueble en sus distintas esferas, que es el reto que la autora ha colocado frente a nosotros. Para ello nos ha entregado herramientas que nos inducen a pensar y a trabajar: un espejo para mirar nuestro quehacer actual, un microscopio para escudriñar y comprender el presente, y desde luego, una silla para apreciar el potencial creativo que subyace en la industria nacional y concebir un futuro realizable, basado en nuestras capacidades para crear valor a través del esfuerzo creativo y la innovación. 